\title{
Biogás: aproveitamento energético e gestão ambiental em aterro sanitário
}

A poluição ambiental pelos resíduos sólidos urbanos está muito ligada à geração do biogás. Entretanto, de poluente, esse gás pode passar a representar uma importante fonte de eletricidade contribuindo para o desenvolvimento sustentável e diversificando a matriz elétrica brasileira. Aliado a melhorias de práticas de gestão, consegue-se alcançar a combinação entre aproveitamento energético e a redução da emissão de gases de efeito estufa. O presente trabalho propõe avaliar a viabilidade econômica do aproveitamento energético do biogás do aterro sanitário do Consórcio de Andradas-MG, além de analisar a redução de gases de efeito estufa em diferentes cenários hipotéticos de gerenciamento de resíduos sólidos urbanos. Considerouse uma projeção de geração de resíduos sólidos urbanos para 20 anos de funcionamento do aterro, cuja produção de biogás foi estimada por meio do software LandGEMC. As emissões de se uma projeção de geração de resíduos sólidos urbanos para 20 anos de funcionamento do aterro, cuja produção de biogás foi estimada por meio do software LandGEMC. As emissões de
gases de efeito estufa foram estimadas aplicando-se o modelo Waste Reduction Model (WARM(), considerando três cenários de gerenciamento de resíduos. A análise de viabilidade econômica foi realizada por meio dos indicadores de valor presente líquido (VPL), taxa interna de retorno (TIR) e custo nivelado de energia (LCOE). Para uma potência de $300 \mathrm{~kW}$, 0 aproveitamento energético do biogás produzido pelo aterro foi de $1,57 \mathrm{GWh} / \mathrm{ano}$, em um período de 20 anos. O projeto apresentou viabilidade econômica, com um VPL de mais de R\$ 3.300.00,00 e TIR de 13,15\%, tendo o retorno econômico pelo sistema após 9 anos. Para a administração do consórcio, gera-se uma oportunidade de reinvestimento de mais de R\$ 865.000,00, com o abatimento do consumo atual de energia dos municípios integrantes do consórcio. A redução mais expressiva da emissão de gases de efeito estufa foi de 115.754,03 MTCO2E, obtida no segundo cenário, o qual priorizou melhorias quali-quantitativas para o gerenciamento dos resíduos.

Palavras-chave: Gestão de Resíduos Sólidos Urbanos; Energia Biogás; Energia renovável; Sustentabilidade; Administração pública.

\section{Biogas: energy use and environmental management in sanitary landfill}

\begin{abstract}
Environmental pollution by solid urban waste is closely linked to the generation of biogas. However, as a pollutant, this gas can become an important source of electricity, contributing to sustainable development and diversifying the Brazilian electrical matrix. Combined with improvements in management practices, it is possible to achieve the combination of energy use and the reduction of greenhouse gas emissions. The present article proposes to evaluate the economic viability of the energy use of biogas from the landfill of the Consortium located in Andradas$\mathrm{MG}$, in addition to analyzing the reduction of greenhouse gases in different hypothetical scenarios of solid urban waste management. It was considered a projection of generation of solid urban waste for 20 years of operation of the landfill, whose biogas production was estimated using the software LandGEM @. Greenhouse gas emissions were estimated using the Waste urban waste for 20 years of operation of the landfill, whose biogas production was estimated using the software LandGEM $\odot$. Greenhouse gas emissions were estimated using the Waste
Reduction Model (WARM $\odot$ ), considering three waste management scenarios. The economic feasibility analysis was carried out using the indicators of net present value (NPV), internal rate of return (IRR) and level cost energy (LCOE). For a power of $300 \mathrm{~kW}$, the energy utilization of the biogas produced by the landfill was $1.57 \mathrm{GWh} / \mathrm{year}$, over a period of 20 years. The project was economically viable, with a NPV of more than $\mathrm{R} \$ 3,300.00 .00$ and an IRR of $13.15 \%$, with an economic return through the electricity generator system after 9 years. For the management of the consortium, an opportunity for reinvestment of more than $R \$ 865,000.00$ is generated, with the reduction of the current energy consumption of the municipalities that are part of the consortium. The most significant reduction in greenhouse gas emissions was $115,754.03 \mathrm{MTCO} E$, obtained in the second scenario, which prioritized qualitative and quantitative improvements for waste management.
\end{abstract}

Keywords: Urban Solid Waste Management; Biogas energy; Renewable energy; Sustainability; Public administration.

Topic: Desenvolvimento, Sustentabilidade e Meio Ambiente

Reviewed anonymously in the process of blind peer.
Received: 03/03/2021

Approved: 26/03/2021
Ulisses Raad Coelho

Universidade Federal de Itajubá, Brasil http://lattes.cnpq.br/9289799550308671

http://orcid.org/0000-0002-4789-2603

ulissesrcoelho@gmail.com

Pedro Marcelo de Moraes Mendonça Universidade Federal de Itajubá, Brasil http://lattes.cnpq.br/9959703622205975 http://orcid.org/0000-0002-3932-3371 pedro.marcelo.mendonca@gmail.com

Sara Talita Sales Silva (id

Universidade Federal de Itajubá, Brasil http://lattes.cnpq.br/6937393414856538 http://orcid.org/0000-0003-3498-9358 saratalitass3@gmail.com
Regina Mambeli Barros

Universidade Federal de Itajubá, Brasil http://lattes.cnpq.br/9289407545513503

http://orcid.org/0000-0003-3154-2956

mambeli@unifei.edu.br
Referencing this:

COELHO, U. R.; MENDONÇA, P. M. M.; SILVA, S. T. S.; BARROS, R. M.. Biogás: aproveitamento energético e gestão ambiental em aterro sanitário. Revista Ibero Americana de Ciências Ambientais, v.12, n.3, p.540-553, 2021. DOI: http://doi.org/10.6008/CBPC2179$\underline{6858.2021 .003 .0044}$ 


\section{INTRODUÇÃO}

Desde os primórdios já se foi observado que os restos de comida, papel e outros subprodutos das atividades humanas, perdiam a utilidade depois de consumidos, por tanto esses subprodutos foram denominados como lixo. Estudos foram feitos para os melhores destinos a esses lixos residuais, trazendo aperfeiçoamento para ambos, expandindo o mercado de trabalho com a criação de incineradores, aterros ou reciclagem, o que também foi importante para evolução do ser humano (POLETTO, 2008; SILVA, 2012). O início da industrialização ocupou o lugar dos produtos artesanais, gerando o consumo excessivo, tendo então que aumentar a produção para comportar a demanda. Essa massificação fez com que surgissem inúmeros impactos ambientais, tais como lançamentos de esgoto a céu aberto, emissão de gases poluentes e vapores químicos, dentre eles o metano $\left(\mathrm{CH}_{4}\right)$ (MONTAÑO, 2016).

A Política Nacional de Resíduos Sólidos (PNRS), instituída pela Lei 12.305 de 2010 e regulamentada pelo Decreto 7.404 do mesmo ano, estabeleceu o novo marco legal para o setor de resíduos sólidos. Com isso, estabeleceu-se uma série de metas, direcionamentos e exigências em todas as esferas governamentais, bem como as obrigações do setor privado. Uma das exigências foi o fim do uso dos lixões em todo território nacional e a determinação para que os governos elaborassem Planos de Resíduos Sólidos, assegurando o controle social em todas as etapas de planejamento e implementação.

Além disso, a PNRS destacou o tema quando estabeleceu que os consórcios públicos constituídos, com o objetivo de viabilizar a descentralização e a prestação de serviços públicos que envolvessem resíduos sólidos, tivessem prioridade na obtenção dos incentivos instituídos pelo Governo Federal. O Ministério do Meio Ambiente (BRASIL, 2020) tem apoiado estados e municípios brasileiros na regionalização e formação de consórcios públicos intermunicipais ou interfederativos para gestão dos resíduos sólidos, por ter identificado na gestão consorciada, por razões de escala, a possibilidade para que pequenos municípios alcancem as metas para gestão de resíduos sólidos, haja vista a redução dos custos, que são rateados. 0 ganho de escala, conjugado com a profissionalização da gestão e implantação da cobrança pela prestação do serviço de coleta e tratamento de RSU, pode contribuir para a autossuficiência econômica do sistema de gestão e gerenciamento.

A PNRS também revela novas frentes de negócios na valorização dos resíduos, incentiva a geração de renda, inclusão de catadores e também chama atenção para a Gestão Legal na constituição e no funcionamento das cooperativas e associações. E também trouxe como alguns dos objetivos, a adoção, desenvolvimento e aprimoramento de tecnologias apropriadas de forma a minimizar impactos ambientais inerentes à gestão e disposição dos resíduos, prevendo, inclusive, a recuperação e o aproveitamento energético como alternativas para tal finalidade (BRASIL, 2010).

O setor de resíduos é responsável por $18 \%$ da emissão antropogênica mundial de $\mathrm{CH}_{4}$ (BOGNER et al., 2008). Participação essa muito significativa, e justamente por isso, é imprescindível que os aterros sanitários adotem tecnologias para mitigação da emissão destes gases, tecnologias como recuperação energéticas dos gases de aterro ou a queima dos mesmos. Nas regiões metropolitanas os aterros sanitários 
são os principais contribuintes na geração de gases de efeito estufa (GEE) como o gás carbônico $\left(\mathrm{CO}_{2}\right)$ e o metano $\left(\mathrm{CH}_{4}\right)$, principais constituintes do biogás (BORBA et al., 2018). Gases estes que mais contribuem para o aquecimento global.

Outro impacto ambiental associado aos aterros é a possível contaminação do solo e do lençol freático quando o aterro não é projetado de forma eficaz para coleta e tratamento do chorume. 0 potencial de poluição residual nestes casos é elevado, a presença de contaminantes em aquíferos é detectada mesmo após anos do encerramento do aterro (AHMED et al., 2001).

Os Resíduos Sólidos Urbanos (RSU) no Brasil são constituídos, em média, de 52\% em Matéria Orgânica (NASCIMENTO et al., 2019). Graças a essa participação, os RSU possuem um elevado potencial energético, devido à geração do biogás da digestão anaeróbia, uma mistura de gases com poder calorífico de até $5.800 \mathrm{kcal} / \mathrm{m}^{3}$. Estima-se que cada tonelada de resíduo disposto possua um potencial energético da ordem de 0,1 a 0,2 MWh (REICHERT, 2014).

Quanto às fontes da matriz energética brasileira, a oferta é de $46,1 \%$ para fontes renováveis tais como fontes hidráulicas, a biomassa, a lenha e carvão vegetal e outras. Já a parcela de fontes não renováveis detém o maior percentual, 53,9\%, e conta com matérias-primas tais como o petróleo e derivados, gás natural, carvão mineral, urânio e outras. Na parcela de fontes renováveis, as "outras renováveis" representam 7\% da matriz e desse percentual, o biogás é responsável por apenas 1,3\%. Por outro lado, a matriz elétrica conta com $83 \%$ de fontes renováveis, esse elevado percentual se deve especialmente pela presença da energia hidráulica, que contribui com $66,6 \%$ do total. Isso demonstra a concentração e a dependência que o país ainda possui em relação a essa fonte (EPE, 2020).

Já no que diz respeito à demanda de energia, o Brasil segue uma tendência crescente pelo uso de energia na forma de eletricidade. Dados no Ministério de Minas e Energia (EPE, 2019) demonstram uma projeção de consumo de eletricidade de ao menos 3,8\% a.a. entre 2019 e 2023. Assim, a necessidade de diversificação da matriz elétrica e a tendência de aumento do consumo de energia, são fatores que, juntos, impulsionam a busca por outras fontes renováveis, tais como a energia do biogás de RSU (CARVALHO, 2019). Segundo informações disponibilizadas pelo Sistema de Informações de Geração da Agência Nacional de Energia Elétrica (ANEEL), atualmente no país, existem vinte e uma usinas instaladas para geração de eletricidade que utilizam como combustível o biogás de aterro sanitários, com uma potência outorgada de 17.440,60 kW (ANEEL, 2020a).

Assim, nesse contexto, este trabalho visa a avaliação econômica do aproveitamento energético do biogás do aterro sanitário pertencente ao consórcio de Andradas, no estado de Minas Gerais. Além disso, busca fornecer um estudo de alternativas de práticas de gerenciamento para a redução da emissão de gases de efeito estufa (GEE) e consumo energético ao longo do ciclo de vida dos materiais.

\section{METODOLOGIA}

\section{Local de estudo}


Neste trabalho foi desenvolvido um estudo para o Consórcio Público Para Gestão Integrada, situado no município de Andradas no sul do Estado de Minas Gerais, integrando a mesorregião Sul/Sudoeste de Minas e a microrregião de Poços de Caldas a uma altitude de $920 \mathrm{~m}$. O consórcio de Andradas atende à uma população total de aproximadamente 80.000 habitantes (IBGE, 2020). Formado em 2014, é constituído pelos municípios de Andradas, Ibitiúra de Minas, Caldas, Santa Rita de Caldas e Ipuiuna, os quais são próximos ao consórcio. Dentre eles, Ipuiuna é o mais distante à 55 km, conforme Figura 1.

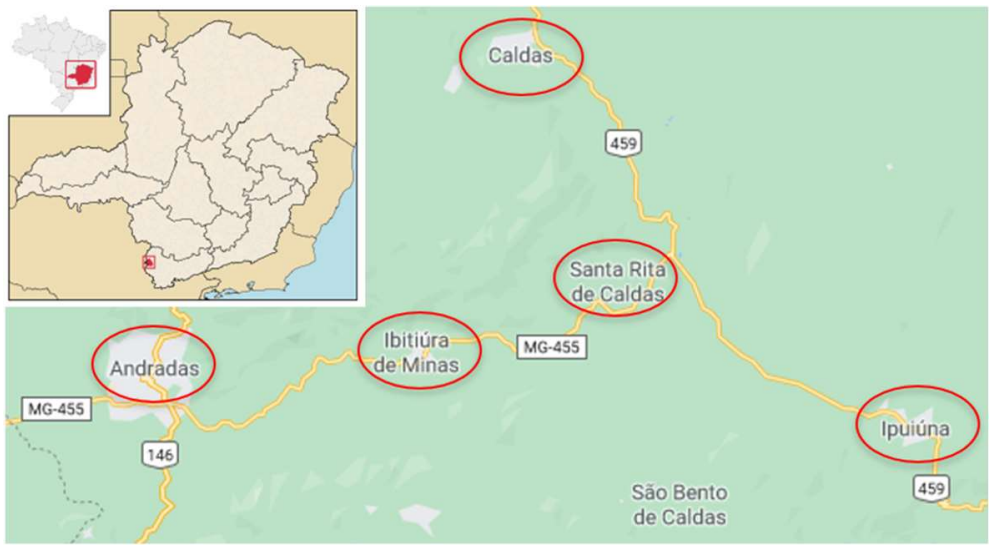

Figura 1: Localização e Cidades que compõem o consórcio. Fonte: Adaptado de Google Earth (2020).

Até o ano de 2013, os resíduos eram destinados a um lixão do município que, em 2014, passaram a ser destinados para o aterro. O município o regularizou no mesmo ano, com o início da operação do aterro sanitário, localizado aproximadamente a $6 \mathrm{~km}$ do centro da cidade. Segundo a Prefeitura Municipal de Andradas (2013), a coleta seletiva em Andradas ocorre de forma informal e desordenada, e que, apesar de formado em 2014, ainda não conta com processo de triagem para reciclagem.

\section{Projeção populacional}

A quantidade de habitantes de um município é informação fundamental para o gerenciamento dos RSU, pois é a partir da projeção do crescimento populacional que se dimensiona a geração de resíduo. Para uma estimativa do crescimento populacional com base em dados históricos dos censos e contagem populacional, do IGBE - Instituto Brasileiro de Geografia e Estatística nos anos de 1999, 2001 e 2010, adotouse a projeção populacional para um período de 20 anos. Os modelos matemáticos escolhidos foram o de crescimento geométrico e o logístico (BARROS, 2013), considerando-se a melhor adequação ao comportamento passado e as expectativas para a região quanto à dinâmica populacional.

Projeção geométrica: Crescimento populacional baseado em uma taxa constante e em função do instante e da população. A curva pode ser ajustada por análise da regressão e a população final não é limitada por uma população de saturação.

Crescimento logístico: O crescimento populacional tem o comportamento de uma curva em forma de "S". Uma população de saturação é obtida e a projeção tende assintoticamente a ela. Os ajustes também podem se estimados por regressão não linear. As condições necessárias para a utilização desse modelo matemático são: $P_{0}<P_{1}<P_{2}$ e $P_{0} \cdot P_{2}<P_{1}{ }^{2}$, com a necessidade de os períodos de tempo serem equidistantes. 
A Tabela 1 mostra as formulas e forma de curva de cada método populacional.

Tabela 1: Modelos matemáticos de projeção populacional utilizados.

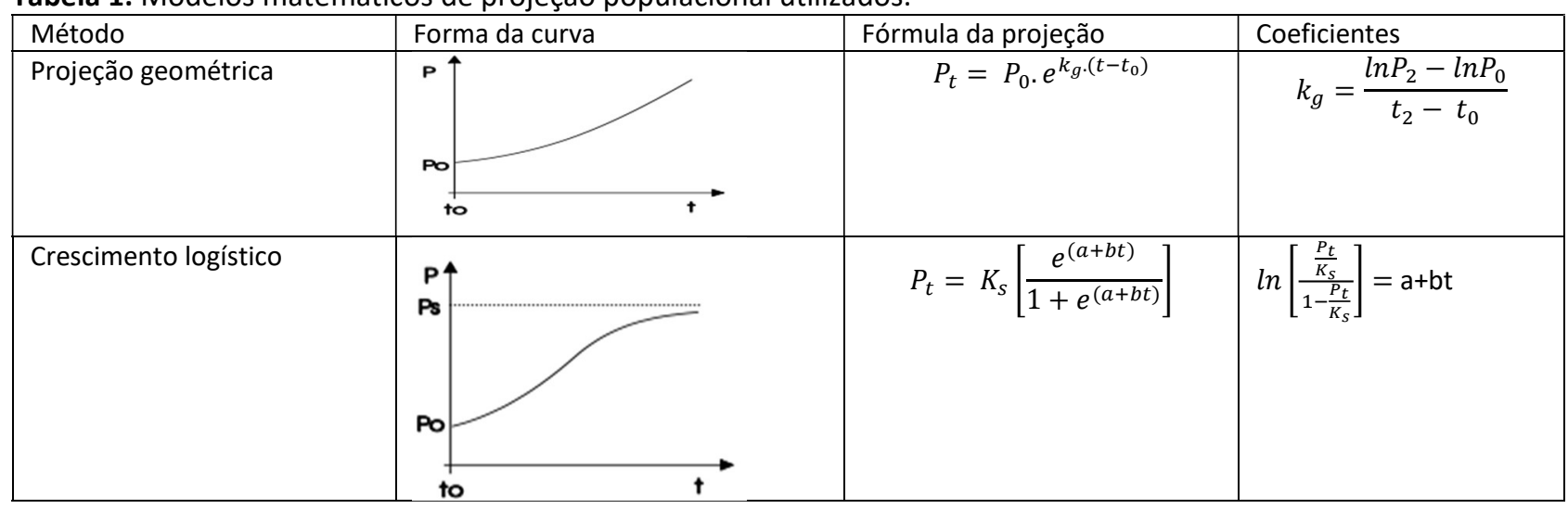

Fonte: Adaptado de Barros (2013).

\section{Onde:}

$P_{0,1,2}=$ população no ano $t_{0,1,2}$

$k_{g}=$ coeficiente de regressão

$P_{t}=$ população em tempo $\mathrm{t}$;

$K_{s}=$ valor máximo de $\mathrm{P}$ (população de saturação);

$\mathrm{a}$ e $\mathrm{b}=$ coeficientes de regressão;

$t_{0,1,2}=$ tempo (anos).

\section{Estimativa de geração de RSU}

Para estimativa da geração de RSU dos municípios pertencentes ao Consórcio de Andradas, foi necessário encontrar a geração per capita de resíduos de cada município. Estes dados foram obtidos diretamente com o consórcio de Andradas, apenas para o município de Santa Rita do Caldas, os dados foram obtidos do Painel de RSU do Sistema Nacional de Resíduos Sólidos Urbanos (SNIS, 2020). Foi considerado um aumento anual de geração per capita de resíduos de 1\%, como utilizado por Barros (2013).

Possuindo a estimativa populacional dos municípios ao longo dos 20 anos considerados, e a geração per capita, calcula-se a geração RSU de cada município multiplicando a População estimada pela geração per capita encontrada. A geração total de RSU do Consórcio é dada pelo somatório da geração de RSU de cada município ao longo dos vinte anos projetados.

\section{Estimativa de geração de metano}

Para a estimativa de biogás e metano gerado pelo aterro do consórcio foi utilizado o software LandGEMC desenvolvido em ambiente Microsoft Office Excel e criado pela Agência de Proteção Ambiental dos Estados Unidos (EPA, 2005). O programa pode ser encontrado gratuitamente no endereço do EPA ${ }^{1}$.

O modelo utiliza a equação 1 para estimar o potencial de geração de metano.

$$
Q_{C H_{4}}=\sum_{i=1}^{n} \sum_{j=0,1}^{1} k L o \frac{M_{t} e^{k t_{i j}}}{10}(1)
$$


$\mathrm{k}$ = taxa de geração de metano;

Lo = capacidade potencial de geração de metano $\left(\mathrm{m}_{3} / \mathrm{Mg}\right)$;

$\mathrm{Mt}=$ massa de resíduos aceitada do enésimo ano $\mathrm{Mg}$;

$\mathrm{Ti,j}$ = idade da j-ésima seção de massa de resíduo Mi, aceita no enésimo ano (anos em número decimal, p. ex. 3,2 anos).

As informações inseridas no programa para a estimativa são: ano de abertura (2020) e de encerramento (2040) do aterro, capacidade potencial de geração de metano (170 m3/ Mg) e o total de resíduo depositado no aterro a cada ano de funcionamento.

\section{Análise econômica}

De posse da estimativa de geração de metano $\left(\mathrm{m}^{3} / \mathrm{ano}\right)$, calculou-se a potência a ser gerada pela queima do metano a cada ano, conforme a equação 2. Para as variáveis de eficiência do motor (E) de combustão interna e eficiência de coleta de biogás $(E c)$, adotou-se respectivamente $E=33 \%, E c=75 \%$ (BARROS et al., 2013).

$$
P x=\frac{Q x \cdot P c(\text { metano })}{31.536 .000} \cdot E \cdot E C \cdot \frac{k}{1000}(2)
$$

Onde:

Px = potência disponível por ano $(\mathrm{kW})$; $\mathrm{Qx}=$ vazão de metano por ano $\left(\mathrm{m}^{3} \mathrm{CH}_{4} / \mathrm{ano}\right)$; $\mathrm{Pc}=$ poder calorífico do metano $\left(35,53 \times 10^{6} \mathrm{~J} / \mathrm{m}^{3} \mathrm{CH} 4\right)$; $\mathrm{E}=$ eficiência da turbina/motor (\%);

Ec = eficiência de coleta de biogás (\%); 31.536.000 s = número de segundos em 1 ano; $\mathrm{k}=1,0$ (adimensional) transformação de unidade de $\mathrm{J} / \mathrm{s}$ para $\mathrm{kW}$;

Assim, a energia máxima a ser gerada ( $\mathrm{kWh} / \mathrm{ano}$ ) foi obtida ao se considerar o fator de capacidade (FC) de 0,6 e o número de horas em um ano $(8760$ h). Para os cálculos de receita (R\$/ano), adotou-se a tarifa praticada no estado, $\mathrm{R} \$ 0,74$ (CEMIG, 2020), considerando que o empreendimento deve compensar os custos do aterro sanitário e dos órgãos públicos com energia. Para elevar a atratividade do projeto, selecionou-se os 20 anos de maior energia gerada. Na sequência, adotou-se uma potência fixa, tendo como critério a menor potência comercial viável e vantajosa do período. Dessa forma, foi possível estimar o investimento inicial ao adotar-se a equação (3), proposta por Silva et al. (2017). Os coeficientes da equação foram obtidos graficamente pelas curvas de correlação entre potência instalada e custos iniciais de investimento.

$$
\text { custo }(U \$ \$)=3631 . P(k W)+157(3)
$$

Onde,

$P$ : potência instalada em kW; Custo: custo inicial de investimento em U\$\$; Valor em R\$ adotado para 1 U\$\$: R\$ 5,53 (BACEN, 2020).

A partir desse valor obtido, calculou-se os custos com operação e manutenção (O\&M) como $5 \%$ do investimento inicial ao ano e realizou-se os fluxos de caixa do período.

O cálculo do valor presente líquido (VPL), utilizado para verificar a viabilidade econômica do projeto, baseou-se na equação 4 (PIN et al., 2017). A taxa de desconto (ou taxa mínima de atratividade - TMA) adotada, foi de $6,46 \%$ a.a., o que corresponde à taxa de reajuste média da tarifa da concessionária no estado onde o consórcio se situa, entre 2011 e 2020 (ANEEL, 2020b).

$$
V P L=\sum_{j=1}^{n} \frac{F C t}{(1+T I R)^{t}}-I o(4)
$$


Para verificar a atratividade do projeto, calculou-se taxa interna de retorno (TIR) (5), ou seja, aquela taxa que tornaria o VPL nulo. Portanto, o projeto torna-se atrativo quando a TIR supera a $r$.

$$
0=\sum_{j=1}^{n} \frac{F C t}{(1+T I R)^{t}}-I o(5)
$$

Por fim, obteve-se Custo Nivelado de Energia (LCOE) (R\$/KWh), no intuito de se analisar o comportamento dos custos de geração ao longo dos anos e comparar esses custos com a tarifa de cobrança de consumo (6).

$$
L C O E=\frac{C T}{E P}(6)
$$

LCOE: custo nivelado de energia;

CT: custos totais do projeto, incluindo construção, operação e outros; EP: energia total produzida ao no tempo do empreendimento.

Apesar do objetivo de aproveitamento energético, os aterros sanitários (AS's) devem ser considerados apenas para a disposição de rejeitos (BRASIL, 2010). Sendo assim, o estudo buscou apresentar alternativas de práticas de gestão que pudessem gerar menores impactos ambientais. Para tanto, utilizou-se o software WARMC (Waste Reduction Model) (US EPA, 2010), um modelo de redução de resíduos criado pela United States Environmental Protection Agency (US EPA), capaz de estimar reduções das emissões de GEE e economia de energia ao longo da cadeia de produção. Assim, o software permite a elaboração de cenários distintos para diversas práticas de gestão eficiente disponíveis (PIN et al., 2017). Como requisito básico para o WARM (C) utilizou-se os dados de geração total anual de resíduos sólidos do consórcio, estimada para o ano de 2020, e a composição gravimétrica adotada (Tabela 2) (BRASIL, 2012).

Tabela 2: Estimativa da composição gravimétrica dos RSU coletados no Brasil. Fonte: elaborado a partir de Brasil (2012).

\begin{tabular}{ll}
\hline Resíduos & Participação \\
\hline Material reciclável & $\mathbf{3 1 , 9 0 \%}$ \\
Metais & $\mathbf{2 , 9 0 \%}$ \\
Aço & $2,30 \%$ \\
Alumínio & $0,60 \%$ \\
Papel, papelão e tetrapack & $13,10 \%$ \\
Plástico total & $\mathbf{1 3 , 5 0 \%}$ \\
Plástico filme & $\mathbf{8 , 9 0 \%}$ \\
Plástico rí́gido & $4,60 \%$ \\
Vidro & $2,40 \%$ \\
Matéria orgânica & $\mathbf{5 1 , 4 0 \%}$ \\
Outros & $\mathbf{1 6 , 7 0 \%}$ \\
\hline Total & $\mathbf{1 0 0 , 0 0 \%}$ \\
\hline
\end{tabular}

As emissões calculadas são dadas em toneladas métricas de carbono equivalente $\left(\mathrm{MtCO}_{2} \mathrm{E}\right)$ e a energia economizada é expressa em British Thermal Unit (BTU). Assim, é possível realizar a comparação entre cenários que considerem alterações nas práticas de gerenciamento tais como, redução na fonte, reciclagem, combustão, compostagem e destinação final dos resíduos sólidos aos AS's. Os cenários elaborados avaliaram 
as seguintes alterações no cenário base: Cenário 0 (CO): Representa a condição atual de gerenciamento de resíduos sólidos no consórcio. Todos os resíduos gerados são destinados ao aterro sanitário; Cenário 1 (C1): Visou a melhoria da qualidade da triagem. Considerou o incremento das práticas de reciclagem para gerar um aumento de 32\% do aproveitamento total dos resíduos recicláveis; Cenário 2 (C2): Visou a melhoria da qualidade da triagem e um ganho em quantidade triada. Adotou-se um aumento de $25 \%$ em relação ao Cenário 1 e aumento de 57\% em relação ao total dos resíduos reciclados; Cenário 3 (C3): Visou manter a proposta do Cenário 2 e considerar o uso energético dos recicláveis por combustão. Manteve o índice de reciclados em $57 \%$, destinando dessa parcela, $18 \%$ para a combustão.

Os cenários foram simulados considerando-se a realidade brasileira de gestão de resíduos sólidos urbanos e conforme graus progressivos de exigência das medidas: conservador (C1), intermediário (C2) e agressivo (C3). Ressalta-se a distinção entre a abordagem de elaboração e de comparação. A primeira utiliza como referência os cenários anteriores, já a segunda, considera o CO como referência inicial. Além disso, optou-se por enfatizar mudanças na gestão de resíduos recicláveis, uma vez que alterações na gestão desse grupo, permite a compatibilização com o estudo de geração de energia.

\section{RESULTADOS E DISCUSSÃO}

\section{Projeção populacional}

A partir dos dados do IBGE dos anos de 1991, 2000 e 2010 e da metodologia apresentada, construiuse a projeção populacional para todos os municípios a fim de verificar qual taxa de crescimento apresentaram valores mais coerentes para este estudo. A população total projetada foi de 80.049 habitantes em 2020, aumentando para 87.518 no ano de 2040. Ao longo de vinte anos, percebe-se um crescimento populacional modesto nas populações do consórcio. A Figura 2 apresenta as projeções populacionais de todos os municípios integrantes do consórcio no período e o comportamento da curva consolidada.

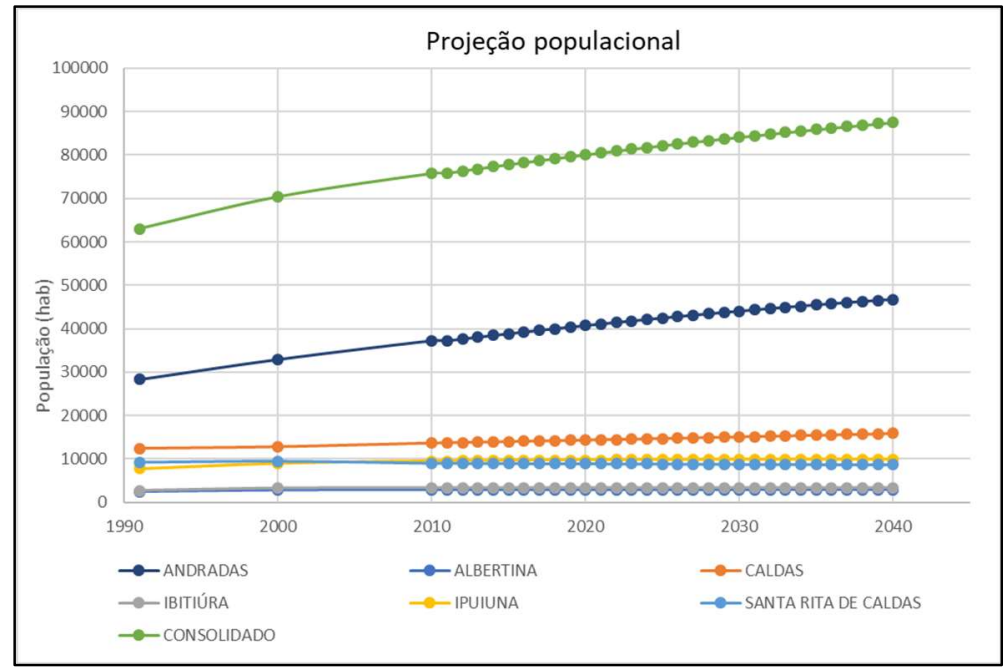

Figura 2: Projeção Populacional dos municípios do consórcio de Andradas (MG).

A Figura 3 demonstra a participação populacional de cada município em 2020 e o município de Andradas representa mais de $50 \%$ da população total do aterro. 


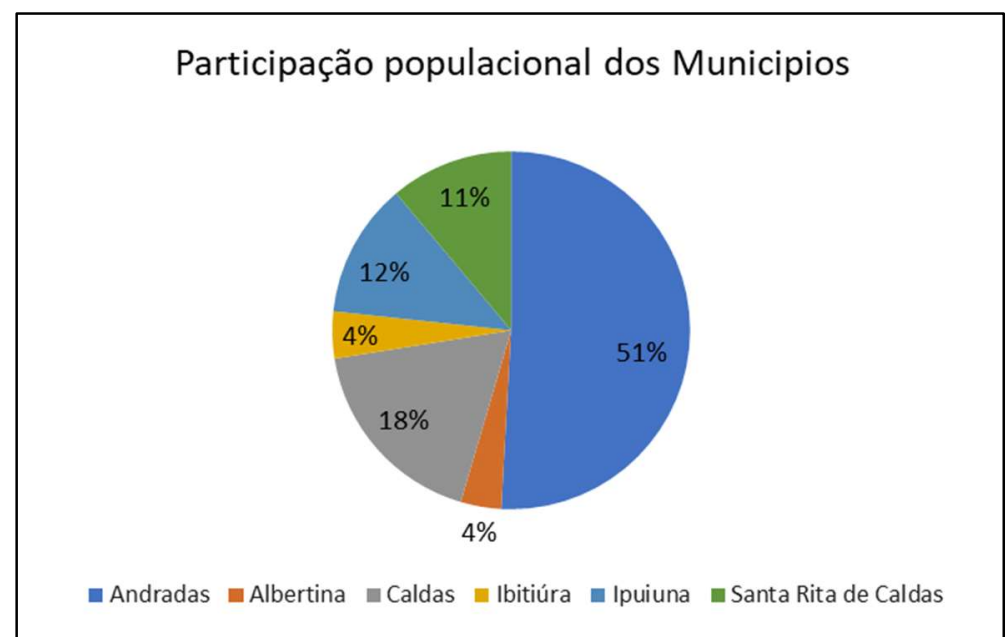

Figura 3: Gráfico da participação populacional dos municípios no consórcio de Andradas (MG). Fonte: Prefeitura Municipal de Andradas (2013).

\section{Estimativa de geração de RSU}

A geração per capita de RSU encontrado, bem como a geração de RSU diária pode ser encontrada na Tabela 3. Para os municípios de Andradas, Albertina, Ibitiúra e Ipuipuna a projeção populacional escolhida foi a de crescimento logístico, já para os municípios de Caldas e Santa Rita de Caldas, a projeção escolhida foi a geométrica. A quantidade de resíduos gerados ano a ano, em $\mathrm{kg}$, pelos municípios pertencentes ao Consórcio e a geração acumulada, pode ser vista na Tabela 4.

Tabela 3: Geração per capita de RSU e geração diária por município participante do Consórcio de Andradas (MG).

\begin{tabular}{|c|c|c|c|c|c|c|}
\hline & \multicolumn{2}{|l|}{ ANDRADAS } & \multicolumn{2}{|l|}{ ALBERTINA } & \multicolumn{2}{|l|}{ CALDAS } \\
\hline Ano & $\begin{array}{l}\text { Geração per capita } \\
\text { (kg/hab./dia) }\end{array}$ & $\begin{array}{l}\text { Geração diária } \\
\text { (kg/dia) }\end{array}$ & $\begin{array}{l}\text { Geração per capita } \\
\text { (kg/hab./dia) }\end{array}$ & $\begin{array}{l}\text { Geração diária } \\
\text { (kg/dia) }\end{array}$ & $\begin{array}{l}\text { Geração per capita } \\
\text { (kg/hab./dia) }\end{array}$ & $\begin{array}{l}\text { Geração diária } \\
\text { (kg/dia) }\end{array}$ \\
\hline 2020 & 0,54 & 21852,16 & 0,38 & 1120,11 & 0,37 & 5276,38 \\
\hline 2021 & 0,54 & 22264,41 & 0,39 & 1131,51 & 0,37 & 5356,44 \\
\hline 2022 & 0,55 & 22679,51 & 0,39 & 1143,00 & 0,38 & 5437,71 \\
\hline 2023 & 0,55 & 23097,42 & 0,39 & 1154,57 & 0,38 & 5520,21 \\
\hline 2024 & 0,56 & 23518,11 & 0,40 & 1166,24 & 0,38 & 5603,97 \\
\hline 2025 & 0,56 & 23941,52 & 0,40 & 1178,00 & 0,39 & 5689,00 \\
\hline 2026 & 0,57 & 24367,62 & 0,41 & 1189,87 & 0,39 & 5775,31 \\
\hline 2027 & 0,58 & 24796,39 & 0,41 & 1201,84 & 0,39 & 5862,94 \\
\hline 2028 & 0,58 & 25227,77 & 0,41 & 1213,92 & 0,40 & 5951,90 \\
\hline 2029 & 0,59 & 25661,75 & 0,42 & 1226,12 & 0,40 & 6042,20 \\
\hline 2030 & 0,59 & 26098,31 & 0,42 & 1238,42 & 0,41 & 6133,88 \\
\hline 2031 & 0,60 & 26537,40 & 0,43 & 1250,85 & 0,41 & 6226,94 \\
\hline 2032 & 0,60 & 26979,03 & 0,43 & 1263,39 & 0,41 & 6321,42 \\
\hline 2033 & 0,61 & 27423,16 & 0,44 & 1276,05 & 0,42 & 6417,34 \\
\hline 2034 & 0,62 & 27869,79 & 0,44 & 1288,83 & 0,42 & 6514,70 \\
\hline 2035 & 0,62 & 28318,90 & 0,44 & 1301,74 & 0,43 & 6613,55 \\
\hline 2036 & 0,63 & 28770,49 & 0,45 & 1314,77 & 0,43 & 6713,89 \\
\hline 2037 & 0,64 & 29224,54 & 0,45 & 1327,94 & 0,44 & 6815,76 \\
\hline 2038 & 0,64 & 29681,06 & 0,46 & 1341,23 & 0,44 & 6919,17 \\
\hline 2039 & 0,65 & 30140,05 & 0,46 & 1354,65 & 0,44 & 7024,15 \\
\hline \multirow[t]{2}{*}{2040} & 0,65 & 30601,50 & 0,47 & 1368,20 & 0,45 & 7130,73 \\
\hline & \multicolumn{2}{|l|}{ IBITIÚRA } & \multicolumn{2}{|l|}{ IPUIPUNA } & \multicolumn{2}{|l|}{ SANTA RITA DE CALDAS } \\
\hline Ano & $\begin{array}{l}\text { Geração per capita } \\
\text { (kg/hab./dia) }\end{array}$ & $\begin{array}{l}\text { Geração diária } \\
\text { (kg/dia) }\end{array}$ & $\begin{array}{l}\text { Geração per capita } \\
\text { (kg/hab./dia) }\end{array}$ & $\begin{array}{l}\text { Geração diária } \\
\text { (kg/dia) }\end{array}$ & $\begin{array}{l}\text { Geração per capita } \\
\text { (kg/hab./dia) }\end{array}$ & $\begin{array}{l}\text { Geração diária } \\
\text { (kg/dia) }\end{array}$ \\
\hline 2020 & 0,46 & 1547,18 & 0,43 & 4200,33 & 0,81 & 7215,27 \\
\hline 2021 & 0,46 & 1562,77 & 0,44 & 4248,79 & 0,82 & 7277,74 \\
\hline 2022 & 0,47 & 1578,50 & 0,44 & 4297,21 & 0,83 & 7340,75 \\
\hline 2023 & 0,47 & 1594,36 & 0,44 & 4345,64 & 0,83 & 7404,30 \\
\hline 2024 & 0,47 & 1610,37 & 0,45 & 4394,11 & 0,84 & 7468,41 \\
\hline
\end{tabular}




\begin{tabular}{|c|c|c|c|c|c|c|}
\hline 2025 & 0,48 & 1626,52 & 0,45 & 4442,66 & 0,85 & 7533,07 \\
\hline 2026 & 0,48 & 1642,83 & 0,46 & 4491,32 & 0,86 & 7598,29 \\
\hline 2027 & 0,49 & 1659,29 & 0,46 & 4540,12 & 0,87 & 7664,07 \\
\hline 2028 & 0,49 & 1675,91 & 0,47 & 4589,09 & 0,88 & 7730,42 \\
\hline 2029 & 0,50 & 1692,69 & 0,47 & 4638,26 & 0,89 & 7797,35 \\
\hline 2030 & 0,50 & 1709,63 & 0,48 & 4687,65 & 0,89 & 7864,86 \\
\hline 2031 & 0,51 & 1726,75 & 0,48 & 4737,29 & 0,90 & 7932,95 \\
\hline 2032 & 0,51 & 1744,02 & 0,49 & 4787,19 & 0,91 & 8001,63 \\
\hline 2033 & 0,52 & 1761,47 & 0,49 & 4837,39 & 0,92 & 8070,91 \\
\hline 2034 & 0,52 & 1779,10 & 0,50 & 4887,90 & 0,93 & 8140,78 \\
\hline 2035 & 0,53 & 1796,89 & 0,50 & 4938,74 & 0,94 & 8211,26 \\
\hline 2036 & 0,54 & 1814,87 & 0,51 & 4989,92 & 0,95 & 8282,35 \\
\hline 2037 & 0,54 & 1833,02 & 0,51 & 5041,47 & 0,96 & 8354,06 \\
\hline 2038 & 0,55 & 1851,35 & 0,52 & 5093,40 & 0,97 & 8426,39 \\
\hline 2039 & 0,55 & 1869,87 & 0,52 & 5145,72 & 0,98 & 8499,34 \\
\hline 2040 & 0,56 & 1888,57 & 0,53 & 5198,45 & 0,99 & 8572,92 \\
\hline
\end{tabular}

Tabela 4: Geração de Resíduos Sólidos do Consórcio de Andradas (MG).

\begin{tabular}{|c|c|c|c|c|c|}
\hline Ano & $\begin{array}{l}\text { População Acumulada } \\
\text { (hab.) }\end{array}$ & $\begin{array}{l}\text { Geração } \\
\text { (Kg/dia) } \\
\end{array}$ & $\begin{array}{l}\text { Geração anual } \\
\text { (Kg/ano) }\end{array}$ & $\begin{array}{l}\begin{array}{l}\text { Geração } \\
\text { (ton/ano) }\end{array} \\
\end{array}$ & $\begin{array}{l}\text { Geração anual acumulada } \\
\text { (ton/ano) }\end{array}$ \\
\hline 2020 & 80049 & 41211 & 15042175 & 15042 & 15042 \\
\hline 2021 & 80483 & 41842 & 15272206 & 15272 & 30314 \\
\hline 2022 & 80911 & 42477 & 15503986 & 15504 & 45818 \\
\hline 2023 & 81332 & 43117 & 15737527 & 15738 & 61556 \\
\hline 2024 & 81747 & 43761 & 15972839 & 15973 & 77529 \\
\hline 2025 & 82154 & 44411 & 16209931 & 16210 & 93739 \\
\hline 2026 & 82555 & 45065 & 16448813 & 16449 & 110187 \\
\hline 2027 & 82950 & 45725 & 16689496 & 16689 & 126877 \\
\hline 2028 & 83338 & 46389 & 16931990 & 16932 & 143809 \\
\hline 2029 & 83719 & 47058 & 17176305 & 17176 & 160985 \\
\hline 2030 & 84095 & 47733 & 17422453 & 17422 & 178408 \\
\hline 2031 & 84464 & 48412 & 17670444 & 17670 & 196078 \\
\hline 2032 & 84827 & 49097 & 17920291 & 17920 & 213998 \\
\hline 2033 & 85184 & 49786 & 18172007 & 18172 & 232170 \\
\hline 2034 & 85535 & 50481 & 18425604 & 18426 & 250596 \\
\hline 2035 & 85880 & 51181 & 18681096 & 18681 & 269277 \\
\hline 2036 & 86219 & 51886 & 18938499 & 18938 & 288216 \\
\hline 2037 & 86552 & 52597 & 19197827 & 19198 & 307413 \\
\hline 2038 & 86880 & 53313 & 19459098 & 19459 & 326873 \\
\hline 2039 & 87201 & 54034 & 19722328 & 19722 & 346595 \\
\hline 2040 & 87518 & 54760 & 19987536 & 19988 & 366582 \\
\hline
\end{tabular}

Observa-se a predominância de geração de RSU para Andradas do início ao final do plano, chegando a $30.601,50 \mathrm{~kg} / \mathrm{dia}$. Isso ocorre devido a sua população, que se apresenta não só como a maior, mas também como a de geração per capta, de 0,65 kg/hab/dia, mais elevada do consórcio.

\section{Estimativa de biogás e metano}

Como pode-se observar na Figura 4, a produção máxima de biogás acontece no ano de 2041, com emissão de 1.249 toneladas, próximo ao ano de fechamento do aterro. Para a geração de dióxido de carbono e de NMOC (compostos orgânicos não metânicos) também é o ano de 2041 o responsável pela máxima emissão, com 3.426 toneladas e 53,7 toneladas, respectivamente. 


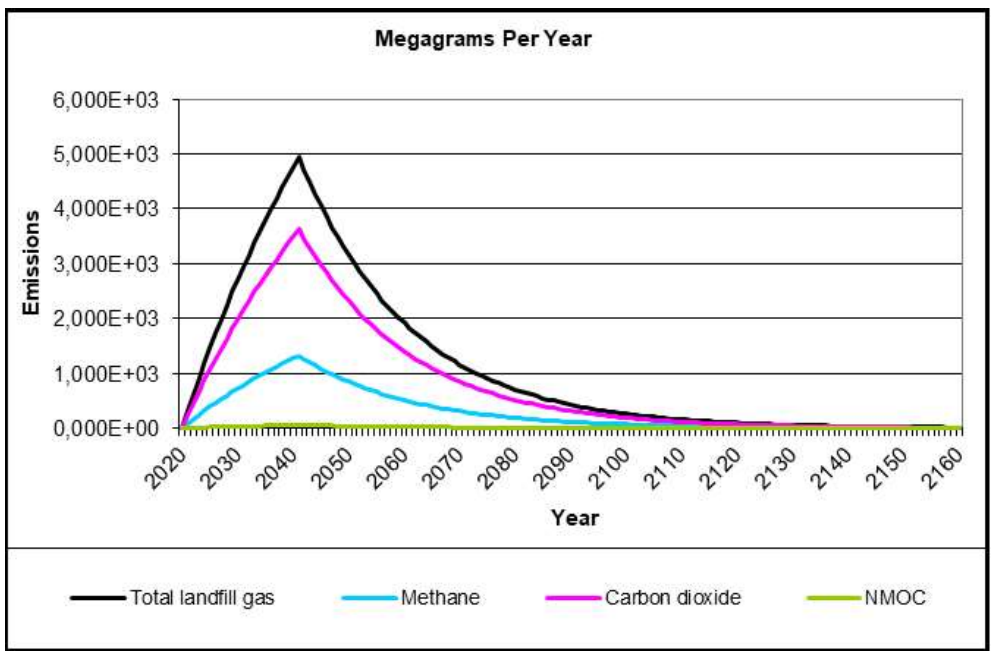

Figura 4: Emissão de gases do Aterro Sanitário de Andradas (MG).

O volume, em $\mathrm{m}^{3}$ /ano, de metano produzido, corresponde a 1.983.374. Esta geração é a considerada para o aproveitamento energético.

\section{Análise econômica}

A potência selecionada para o maior aproveitamento energético, foi de $300 \mathrm{~kW}$ dentro do período de 2030 a 2050, gerando $1.576 .800 \mathrm{kWh} /$ ano (Figura 5). Tem-se, portanto, o enquadramento da proposta como minigeração distribuída, ou seja, com potência instalada entre $75 \mathrm{~kW}$ e $5 \mathrm{MW}$, em um regime de compensação de energia (ANEEL, 2018).

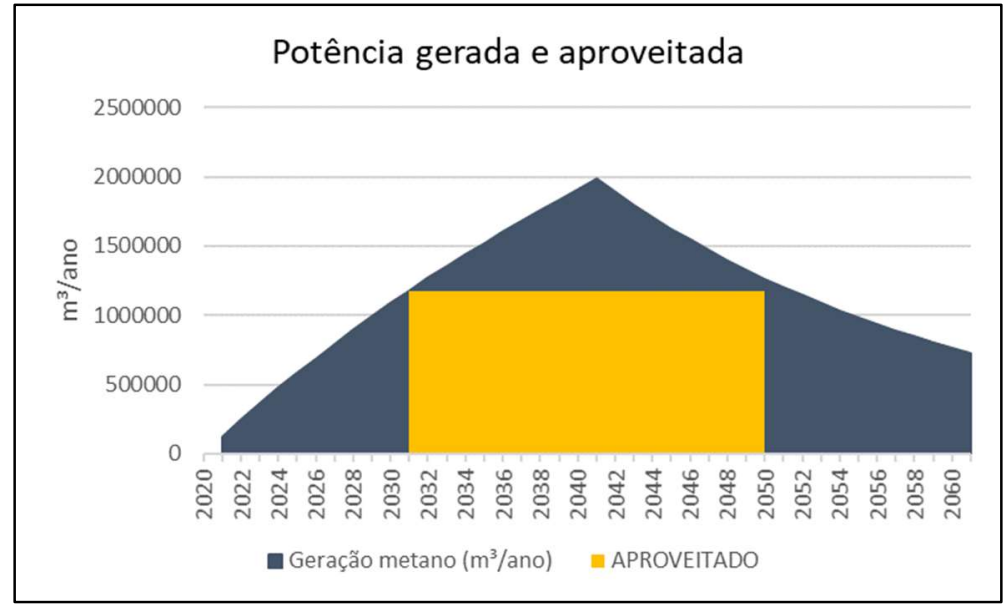

Figura 5: Gráfico do VPL e da TIR entre 2030 e 2050

O custo inicial de implantação do projeto resultou em $\mathrm{R} \$ 6.024 .865,02$, com receita de $\mathrm{R} \$$ 865.588,00/ano e O\&M de R\$301.243,25/ano. Dessa forma, o VPL obtido resultou em $\mathrm{R} \$ 3.325 .034,31 \mathrm{com}$ uma TIR de 13\% a.a. (Figura 6), mostrando-se um empreendimento viável e atrativo economicamente, já que a partir do nono ano (2039) o investimento é recuperado e a TIR do final do projeto é maior do que a TMA. Isso se deve ao fato da opção pelo consumo direto com vistas a abater custos com energia do próprio aterro e instalações públicas. Assim, mesmo não se enquadrando em uma população superior a 200 mil habitantes, apontada por Barros et al. (2013) para que se tenha viabilidade econômica, a proposta se mostrou viável. 


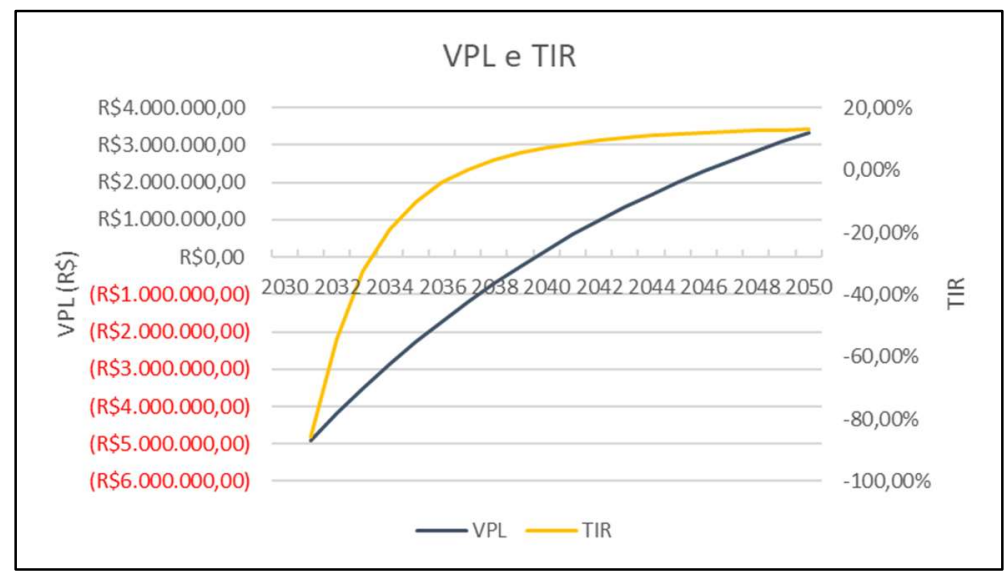

Figura 6: Gráfico do VPL e da TIR entre 2030 e 2050.

Outra forma pela qual se avaliou a viabilidade e o grau de atratividade da proposta foi através do LCOE. Observa-se na Figura 7 que o custo por kWh gerado inicia em $R \$ 4,01$ e alcança $R \$ 0,38$ no último ano do estudo. Nota-se que a partir do sétimo ano (2037) o LCOE se iguala à tarifa adotada de $R \$ 0,74$. Desse ano em diante, observa-se que o custo de geração se torna inferior ao valor em reais da energia gerada. Aliado à sua tendência de redução ao longo dos anos, verifica-se que esse indicador reforça a viabilidade econômica já demonstrada pois endossa, por uma outra perspectiva, o retorno econômico do projeto.

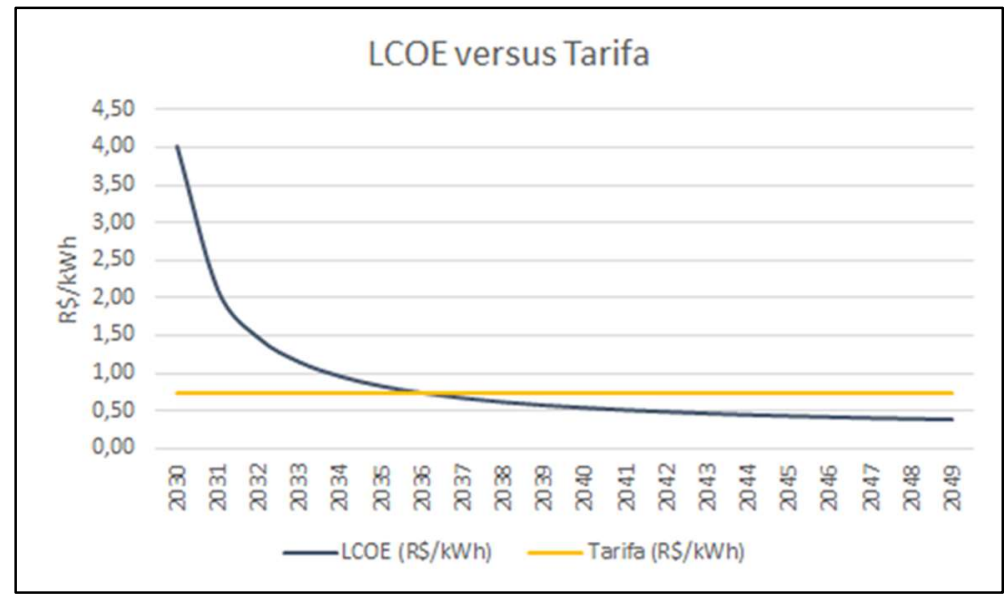

Figura 7: Gráfico do Custo nivelado de energia (LCOE) e Tarifa, entre 2030 e 2050.

\section{Análise da emissão dos GEE}

A da Tabela 5 resume os principais resultados obtidos das alterações propostas de gerenciamento dos resíduos sólidos em cada cenário. Os resultados, expressos em termos de emissão de GEE e uso energético, podem oferecer informações relevantes aos gestores do consórcio para a melhoria e planejamento do sistema, na perspectiva de práticas ambientais mais sustentáveis.

Tabela 5: Resumo dos resultados das simulações de cenários com o WARMC.

\begin{tabular}{llll}
\hline Simulações & Cenários & Emissões totais (MTCO2E) & Uso energético (BTU) \\
\hline \multirow{2}{*}{ C1 versus C0 } & Linha de base & 416,09 & $(553,24)$ \\
& Cenário 1 & $(63.007,68)$ & $(6.998,44)$ \\
& Emissões incrementais & $(63.423,77)$ & $(6.445,20)$ \\
\hline \multirow{2}{*}{ C2 versus C1 } & Linha de base & 416,09 & $(553,24)$ \\
& Cenário 2 & $(115.337,94)$ & $(10.788,19)$ \\
& Emissões incrementais & $(115.754,03)$ & $(10.234,95)$ \\
\hline C3 versus C2 & Linha de base & 416,09 & $(553,24)$
\end{tabular}


Os resultados demonstram reduções nas emissões de GEE e consumo energético em todos os cenários com relação à linha de base, C0. Comparativamente, o cenário mais atrativo para esses dois aspectos foi o 2, reduzindo as emissões em 115.754,03 $\mathrm{MTCO}_{2} \mathrm{E}$ e o consumo energético em 10.234,95 BTU (3 kW). Essa vantagem ocorre uma vez que, em C2, o material reciclado seria reintroduzido no ciclo produtivo, evitando-se a combustão dos resíduos recicláveis e o processo de extração de matéria-prima. Observandose o C3, no qual implementa-se a incineração, nota-se que as emissões aumentaram em relação a C2 e C1, sem que houvesse um ganho energético que justificasse a sua escolha frente aos outros cenários. Assim, pode-se concluir que o investimento qualitativo e quantitativo nos processos de triagem de materiais reciclados (C2), é mais interessante do ponto de vista ambiental, porém também, econômico.

\section{CONCLUSÕES}

As análises de viabilidade econômica, permitiram concluir que é viável o aproveitamento energético do metano do biogás, gerando uma potência de $300 \mathrm{~kW}$. O retorno de investimento a partir do nono ano, com energia gerada de 1,57GWh/ano e uma receita de $\mathrm{R} \$ 865.588,00 /$ ano, se mostram importantes incentivos para a redução de impactos ambientais negativos através do reinvestimento em programas de sustentabilidade energética e ambiental. Podendo contribuir com a diversificação da matriz elétrica brasileira e a redução de impactos ambientais negativos nos aterros sanitários municipais.

Quanto aos cenários avaliados para melhoria das práticas de gestão, o C2 expressa a necessidade do investimento em otimização da reciclagem de resíduos nos municípios, já que essa prática proporciona maiores benefícios ambientais, obtidos pela redução de emissão de GEE's nos aterros sanitários e consumo de energia. Além disso, uma conjugação viável e vantajosa pode se concretizar com a aplicação dos recursos obtidos pela geração energética na melhoria das práticas apontadas pelo C2. Assim sendo, ressalta-se a importância de um maior empenho da gestão pública em direcionar investimentos à infraestrutura, conscientização e educação ambiental da população, corresponsável da gestão sustentável dos RSU.

\section{REFERÊNCIAS}

ANDRADAS. Prefeitura Municipal de Andradas. Plano de Gestão Integrada de Resíduos Sólidos. Andradas: Grupo Brasil Ambiental Consultoria, 2013.

ANEEL. Agência Nacional de Energia Elétrica. Geração Distribuída. Brasília: Superintendência de Regulação dos Serviços de Distribuição (SRD), 2018.

ANEEL. Agência Nacional de Energia Elétrica. Sistema de Informações de Geração (SIGA). Brasília: Superintendências de Concessões e Autorizações de Geração (SCG), 2020a.

ANEEL. Agência Nacional de Energia Elétrica. Tarifas residenciais: efeitos dos reajustes tarifários. Brasília: Superintendência de Gestão Tarifária (SGT), 2020b.
AHMED, A. M.; SULAIMAN, W. N.. Evaluation of groundwater and soil pollution in a landfill area using electrical resistivity imaging survey. Environmental Management, New York, v.28, n.5, p.655-663, 2001. DOI: http://doi.org/10.1007/s002670010250

BACEN. Banco Central do Brasil. Consulta de cotações e boletins. Brasília: Banco Central do Brasil, 2020.

BARROS, R. M.. Tratado sobre resíduos sólidos: Gestão, uso e sustentabilidade. 1 ed. Rio de Janeiro: Interciência, 2013.

BARROS, R. M.; FILHO, G. L. T.; SILVA, T. R.. The Eletric energy potential of landfill biogas in Brazil. Energy Policy, v.65, p.150-164, 2013. DOI:

http://doi.org/10.1016/j.enpol.2013.10.028 
BRASIL. Lei N. 12.305, de 02 de agosto de 2010. Institui a Política Nacional de Resíduos Sólidos; altera a Lei № 9.605, de 12 de fevereiro de 1998; e dá outras providências. Brasília: DOU, 2010.

BRASIL. Plano Nacional de Resíduos Sólidos (PNRS). Brasília: Ministério do Meio Ambiente, 2012.

BRASIL. Plano Nacional de Resíduos Sólidos - Consulta Pública. Brasília: Ministério do Meio Ambiente - Secretaria de Qualidade Ambiental, 2020.

BOGNER, J.; PIPATTI, R.; HASHIMOTO, S.; DIAZ, C.; MARECKOVA, K.; DIAZ, L.; KJELDSEN, P.; MONNI, S.; FAAIJ, A.; SUTAMIHARDJA, R. T. M.; GREGORY, R.. Mitigation of global greenhouse gas emissions from waste: conclusions and strategies from the Intergovernmental Panel on Climate Change (IPCC) Fourth Assessment Report. Working Group III (Mitigation). Waste Management Research, v.26, p.11-32, 2008. DOI: http://doi.org/10.1177/0734242X07088433

BORBA, P. F. S.; MARTINS, E. M.; CORREA, S. M.; RITTER, E.. Greenhouse gases emissions from a landfill in Rio de Janeiro. Engenharia Sanitária e Ambiental, Rio de Janeiro, v.23, n.1, p.101-111, 2018. DOI: http://doi.org/10.1590/S1413$\underline{41522018167438}$

CEMIG. Companhia Energética de Minas Gerais. Valores de tarifas e serviços. Minas Gerais: Companhia Energética de Minas Gerais, 2020.

CARVALHO, R. Q.; TAVARES, A. N.; SANTOS, G. V.; BAJAY, S. V.. Oportunidades Enterradas: Geração elétrica do biogás de RSU. Vitória: EDUFES, 2019.

EPE. Empresa de Pesquisa Energética. 1a Revisão Quadrimestral das Projeções da demanda de energia elétrica do Sistema Interligado Nacional, 2019-2023. Rio de Janeiro: EPE, 2019.

EPE. Empresa de Pesquisa Energética. Balanço Energético Nacional: Relatório Síntese. Rio de Janeiro: EPE, 2020.

IBGE. Instituto Brasileiro de Geografia e Estatística. Pesquisa Nacional do Saneamento Básico 2008. Rio de Janeiro:
Ministério do Planejamento, Orçamento e Gestão, 2010.

MONTAÑO, J.. Resíduos Sólidos, Resíduos Líquidos, Efluentes e Afluentes. Ambientesst, 2016.

NASCIMENTO, M. C. B.; FREIRE, E. P.; DANTAS, F. A. S.; GIANSANTE M. B.. Estado da arte dos aterros de resíduos sólidos urbanos que aproveitam o biogás para geração de energia elétrica e biometano no Brasil. Engenharia Sanitária Ambiental, Rio de Janeiro, v.24, n.1, p.143-155, 2019. DOI: http://dx.doi.org/10.1590/s1413-41522019171125

PIN, B. V. R.; BARROS, R. M.; LORA, E. E. S.; SANTOS, I. F. S.. Waste management studies in a Brazilian microregion: GHG emissions balance and LFG energy project economic feasibility analysis. Energy Strategy Reviews, v.19, p.31-43, 2017. DOI: http://doi.org/10.1016/j.esr.2017.11.002

POLETTO, J. A.. Viabilidade energética e econômica da incineração de resíduo sólido urbano considerando a segregação para reciclagem. Dissertação (Mestrado em Engenharia Mecânica) - Universidade Estadual Paulista, São Paulo, 2008

REICHERT, G. A.. Tecnologias apropriadas para o tratamento dos resíduos sólidos. In: SEMINÁRIO NACIONAL DE RESÍDUOS SÓLIDOS, DESAFIOS PARA IMPLANTAÇÃO DA POLITICA NACIONAL, 11. Anais. Brasília: ABES, 2014.

SILVA, T. R.; BARROS, R. M.; FILHO, G. L. T.; SANTOS, I. F. S.. Methodology for the determination of optimum power of a Thermal Power Plant (TPP) by biogas from sanitary landfill. Waste Management, v.65, p.75-91, 2017. DOI: http://doi.org/10.1016/j.wasman.2017.04.018

SILVA, T. R.. Metodologia para a determinação teórica da potência ótima conseguida a partir da combustão do biogás gerado em aterro sanitário: Estudo de caso do aterro sanitário de Itajubá-MG. (Mestrado em Engenharia de Energia) - Universidade Federal de Itajubá, Itajubá, 2012.

SNIS. Diagnóstico anual de resíduos sólidos. Brasília: Ministério do Desenvolvimento Regional, 2020.

US EPA. Environmental Protection Agency. Waste Reduction Model@ (WARM) - version 15. Washington: US EPA, 2010.

A CBPC - Companhia Brasileira de Produção Científica (CNPJ: 11.221.422/0001-03) detém os direitos materiais desta publicação. Os direitos referem-se à publicação do trabalho em qualquer parte do mundo, incluindo os direitos às renovações, expansões e disseminações da contribuiç̃o, bem como outros direitos subsidiários. Todos os trabalhos publicados eletronicamente poderão posteriormente ser publicados em coletâneas impressas sob coordenação da Sustenere Publishing, da Companhia Brasileira de Produção Científica e seus parceiros autorizados. Os (as) autores (as) preservam os direitos autorais, mas não têm permissão para a publicação da contribuição em outro meio, impresso ou digital, em português ou em tradução. 